\title{
Pharmaciana
}

Vol.10, No.2, July 2020, Page. $135-146$

ISSN: 2088 4559; e-ISSN: 24770256

DOI: $10.12928 /$ pharmaciana.v10i2.16877

\section{Structure, activity, and drug-likeness of pure compounds of Sumatran lichen (Stereocaulon halei) for the targeted ACE2 protein in COVID-19 disease}

\author{
Purnawan Pontana Putra*1, Surya Sumantri Abdullah², \\ Risma Rahmatunisa ${ }^{3}$, Junaidin Junaidin ${ }^{4}$, Friardi Ismed ${ }^{1}$ \\ ${ }^{I}$ Faculty of Pharmacy, Universitas Andalas, \\ Jl. Universitas Andalas, Padang, West Sumatra, Indonesia \\ ${ }^{2}$ Department of pharmacy, Universitas Sam Ratulangi Manado, \\ Jl. Kampus Universitas Sam Ratulangi, Manado, North Sulawesi, Indonesia \\ ${ }^{3}$ Faculty of health sciences, Universitas Singaperbangsa Karawang, \\ Jl. HS. Ronggo Waluyo, Karawang, West Java, Indonesia \\ ${ }^{4}$ College of Pharmacy, Sekolah Tinggi Farmasi Muhammadiyah Tangerang, \\ Jl. KH Syekh Nawawi, Tangerang, Banten, Indonesia
}

Accepted: 20-07-2020

\begin{abstract}
Sumatran lichen has the potential as antiviral, pure isolates that have been isolated and developed as prospective compounds for COVID-19 treatment. Computational methods were used to accelerate the discovery and screening of potential new compounds. The molecular structures of the isolated compounds such as Lobarin, Atranorin, Methyl 2,4-dihydroxy-3,6-dimethylbenzoate, Methyl 3-formyl-2,4-dihydroxy-6-methylbenzoate, Ethyl 3-formyl-2,4-dihydroxy-6-methylbenzoate, and Lobaric acid were drawn, then their activities were analyzed, processed by docking with ACE2 protein, and tested for Druglikeness. The activities and druglikeness were determined in the Swiss ADME program, while the ACE2 docking was processed by Blind Docking in Arguslab, AutoDock Vina, Open Babel, and Discovery Studio Visualizer programs. All compounds bound to the ACE2 protein, as apparent from the number of hydrogen bonds between the two. The Gibbs free energy was in the range of -5.6 to -7.0 , and the best one was obtained from atranorin. As for lobarin, this compound was found to be non-drug-like.
\end{abstract}

Keywords: Sumatran lichen, structural activity, computational, COVID-19

\footnotetext{
*Corresponding author:

Purnawan Pontana Putra

Faculty of Pharmacy, Universitas Andalas

J1. Universitas Andalas, Padang, West Sumatra, Indonesia

Email: purnawanpp@phar.unand.ac.id
} 


\section{INTRODUCTION}

The COVID-19 disease has turned into a worldwide pandemic, with $11,799,443$ positive cases and 543,558 fatalities per July 8, 2020, with a fatality rate of 4.6\% (Hopkins, 2020). Every country has, therefore, applied different techniques to contain the spread, including quarantine and travel restrictions in China, Italy, Spain, India, and Iran and mass testing in South Korea (Dunford et al., 2020).

COVID-19 enters through the pathway of the ACE2 receptor (Wan et al., 2020). ACE2 is presented in type II alveolar epithelial cells, which are the entry point of the SARS-COV2 virus (Zhao et al., 2020). High mortality factors are prevalent in patients with congenital diseases, such as hypertension, diabetes, and heart disease. Understanding the pathway of the virus is a stepping stone to the development of drugs that specifically target ACE2.

A lichen, another name of crust moss, is a plant that emerges from the symbiotic relationship between fungi (mycobionts) and algae and grows in tree trunks, soil, rocks, foreshore, and mountain cliffs (Ranković, 2015). Prior scholars have confirmed the antiviral potential of this plant (Odimegwu et al., 2015). For this reason, this study used Stereocaulon halei (Sumatran lichen), a biotic material native of Indonesia, to identify its potential for treating COVID-19 disease by computational methods and molecular simulations.

The active compounds contained in $S$. halei were investigated by Absorption, Distribution, Metabolism, and Excretion (ADME). ADME prediction can simulate the process of drugs in the body. Toxicity testing provides structural alerts that indicate whether or not the compound observed can cause carcinogens and mutagens. Docking is a simulation method used to determine the orientation between ligands and receptors. Compounds from $S$. halei are docked in the ACE2 protein of the SARS-COV2 virus.

This research employed a blind docking process because the grid box parameters of the Angiotensin-converting enzyme 2 (ACE2) enzyme were unknown. The docking process was semiflexible, in which the receptors used were rigid, while the ligands were flexible. AutoDock Vina is one of the docking programs designed to predict small molecules such as inhibitors attached to receptors in the form of three-dimensional (3D) structures. Basically, AutoDock Vina consists of two main features, which are AutoDock that helps the docking process of ligands to a set of grids that represents the intended protein and AutoGrid that helps the calculation of the grids. A computational method is expected to find prospective natural substance-based drugs for COVID-19 disease.

\section{MATERIALS AND METHODS Materials}

The materials used were the chemical structures of the six compounds isolated from Stereocaulon halei, namely (1) Lobarin, (2) Atranorin, (3) Methyl 2,4-dihydroxy-3,6dimethylbenzoate, (4) Methyl 3-formyl-2,4-dihydroxy-6-methylbenzoate, (5) Ethyl 3-formyl-2,4dihydroxy-6-methylbenzoate, and (6) Lobaric acid. Figure 1 presents the structures of these compounds (Ismed et al., 2012). 
<smiles>CCCCCc1c(OC)cc(OC)cc1Oc1cc(O)cc(O)c1C(=O)O</smiles>

Compound 1. Lobarin<smiles>COC(=O)c1c(C(N)N)cc(OC)c(C(N)(O)I)c1OC</smiles>

Compound 3. Methyl 2,4-dihydroxy-3,6dimethylbenzoate<smiles>CCOC(=O)c1c(C)cc(O)c(C=O)c1O</smiles>

Compound 5. Ethyl 3-formyl-2,4-dihydroxy6-methylbenzoate

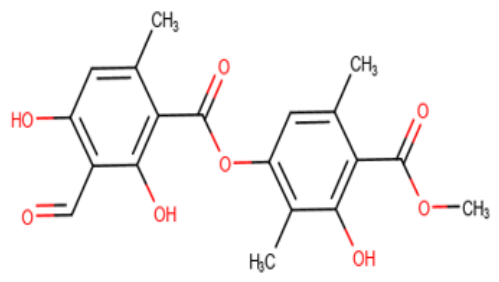

Compound 2. Atranorin<smiles>COC(=O)c1c(C)cc(O)c(C=O)c1O</smiles>

Compound 4. Methyl 3-formyl-2,4dihydroxy-6-methylbenzoate

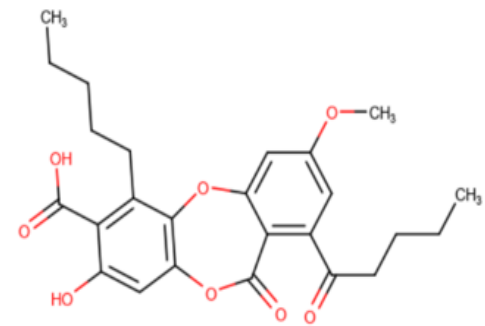

Compound 6. Lobaric acid

Figure 1. The structures of the compounds isolated from Stereocaulon halei (Sumatran lichens)

\section{Software and hardware}

The tools used in this study were computers with Intel® Core (TM) i5-2450 M CPU @ 2.50 $\mathrm{GHz}$ and Intel ${ }^{\circledR}$ Atom ${ }^{\mathrm{TM}} \mathrm{X} 5-\mathrm{Z} 8300 \mathrm{CPU} @ 1.44 \mathrm{GHz}$ (4CPU). The operating systems were Windows 7 and 10 64-Bit. The software used included Marvin Sketch v.16.9.12, OECD QSAR Toolbox v.4.3, Swiss Dock, AutoDock 1.5.6, AutoDock Vina, Argus Lab, OpenBabel, and Discovery Studio Visualizer.

\section{Procedures}

\section{ADME and toxicity}

The 2D structure was drawn in the Marvin Sketch program, and the compound was analyzed according to the name listed in the International Union of Pure and Applied Chemistry (IUPAC). The protonation was adjusted at $\mathrm{pH} \mathrm{7.4,} \mathrm{which} \mathrm{is} \mathrm{the} \mathrm{normal} \mathrm{condition} \mathrm{of} \mathrm{the} \mathrm{human} \mathrm{body.} \mathrm{Then,} \mathrm{the}$ 
chemical structure was analyzed by SwissADME (Absorption, Distribution, Metabolism, and Excretion). As for the toxicity, it was predicted using the structural alert feature provided in QSAR Toolbox.

\section{Ligands and proteins}

The materials used were the 3D macromolecular structures of Angiotensin-converting enzyme 2 (ACE2) (PDB ID: 6M17), obtained from the online database of Protein Data Bank (www.pdb.org), and compounds isolated from Stereocaulon halei.

\section{Ligand preparation}

The ligands used were the isolated compounds of Stereocaulon halei. Their 3D structures were built and processed by the semi-empirical method (PM3) geometry optimization using the Arguslab program. The optimized structures were saved in *.xyz and then converted to *.pdb using the OpenBabel program

\section{Receptor preparation}

The ACE2 macromolecules (GDP: 6M17) were downloaded from the protein data bank (GDP) website, www. rcsb.org. The structure of this protein was displayed in the Discovery Studio Visualizer v.4.5 program package, separated from the water molecules and their natural ligands, then stored in *.pdb and treated as a receptor.

\section{Molecular simulation}

Subsequently, the test compounds were tethered in the receptor using the blind docking method. This method was used because the test receptors were categorically new, still in the process of research and development, and, therefore, had no congenital ligands. Besides, the active side of ACE2 was unknown. The molecular docking was carried out using the AutoDock Vina program. The results of the analysis were free energy bonds, hydrogen bonds, and binding patterns with other amino acid residues at the test receptors.

\section{RESULTS AND DISCUSSION}

\section{Predictions of the chemical-physical properties}

The predicted chemical-physical properties of the pure compounds of Stereocaulon halei were presented in Table 1. These properties included the predicted values of the molecular weight, molar refractivity, topology surface area (TPSA), $\log \mathrm{p}$, and $\log \mathrm{S}$.

Table 1. The predicted chemical-physical properties of compounds isolated from Stereocaulon halei

\begin{tabular}{cccccc}
\hline \multirow{2}{*}{ Compound } & \multicolumn{3}{c}{ Chemical-Physical Properties } & & \multirow{2}{*}{$\log \mathbf{p}$} \\
\cline { 2 - 4 } & Molecular Weight (g/mol) & $\begin{array}{c}\text { Molar } \\
\text { Refractivity }\end{array}$ & TPSA & & \\
\hline 1 & 474.50 & 122.30 & 145.58 & 3.85 & -8.52 \\
2 & 374.34 & 95.48 & 130.36 & 2.78 & -6.78 \\
3 & 196.20 & 51.70 & 66.76 & 1.77 & -3.38 \\
4 & 210.18 & 52.12 & 83.83 & 1.26 & -3.38 \\
5 & 224.21 & 56.93 & 83.83 & 1.61 & -3.76 \\
6 & 455.48 & 120.26 & 122.19 & 4.33 & -8.46 \\
\hline
\end{tabular}


All compounds had molecular masses in the range of 196.20-474.50 g/mol. An orally administered drug can be easily absorbed if the molecular mass is less than $500 \mathrm{~g} / \mathrm{mol}$ (Lipinski, 2004). Molar refractivity is a measure of the steric factor, i.e., the volume occupied by an atom or group of atoms. It is used as a measure of substituent steric influence in the Quantitative StructureActivity Relationship (QSAR) equation (Patrick, 2013).

Topology Polar Surface Area (TPSA) is a 2D-QSAR descriptor that represents a relationship between ligands and specific targets (Prasanna and Doerksen, 2008). Molecules with TPSA values higher than 140 angstroms are inclined to permeate the cell membrane poorly (Pajouhesh and Lenz, 2005). The same case applies to lobarin.

The $\log$ p-value reflects the tendency of a fat-soluble compound. All compounds isolated from Stereocaulon halei had $\log \mathrm{p}$ of $<5$, meaning that they can be easily absorbed through oral administration (Lipinski, 2004). Here, $\log \mathrm{p}$ was the consensus value from various $\log \mathrm{p}$ determination methods. $\log \mathrm{S}$ is the logarithm of water solubility. Based on the $\log \mathrm{S}$ values, lobarin, atranorin, and lobaric acid were categorized as compounds with low water solubility. Meanwhile, methyl 2,4dihydroxy-3,6-dimethylbenzoate, methyl 3-formyl-2,4-dihydroxy-6-methylbenzoate, and ethyl 3formyl-2,4-dihydroxy-6-methylbenzoate were identified as water-soluble compounds.

\section{Pharmacokinetic prediction, drug-likeness, and medicinal chemistry}

The pharmacokinetic model represents the relationship between chemical coordination in tissues, chemical calculations, and ADME processes (El-Masri, 2013). The predicted pharmacokinetic profiles of the compounds observed are summarized in Table 2.

Table 2. Pharmacokinetic profile prediction of compounds isolated from Stereocaulon halei

\begin{tabular}{cccccccccc}
\hline & \multicolumn{10}{c}{ Pharmacokinetic } \\
\cline { 2 - 9 } Compounds & GIA & BBB & $\begin{array}{c}\text { P-gp } \\
\text { Substrate }\end{array}$ & CYP1A2 & CYP2C19 & CYP2C9 & CYP2D6 & CYP3A4 & $\begin{array}{c}\text { Log } \\
\text { Kp } \\
(\mathbf{c m} / \mathbf{s})\end{array}$ \\
\hline 1 & Low & No & No & No & Yes & Yes & No & Yes & -5.14 \\
2 & High & No & No & No & No & No & No & No & -5.51 \\
3 & High & Yes & No & No & No & No & No & No & -5.84 \\
4 & High & No & No & No & No & No & No & No & -6.17 \\
5 & High & No & No & No & No & No & No & No & -5.99 \\
6 & High & No & No & No & Yes & Yes & No & Yes & -4.74 \\
\hline
\end{tabular}

Notes:

GIA = gastrointestinal absorption

$\mathrm{BBB}=$ blood-brain barrier

Pgp-subtrate $=$ P-glycoprotein substrates

Log $\mathrm{Kp}=$ skin permeability coefficient

After oral absorption, the drug permeates the gastrointestinal mucous membrane then enters the blood circulation (Hirtz, 1985). Lobarin had low absorption in the low gastrointestinal membrane, Lobarin had low absorption in the low gastrointestinal membrane, in which this compound is found at high levels in the blood. Also, lobarin has four $\mathrm{OH}$ groups that can decrease gastrointestinal absorption. Atranorin, Methyl 2,4-dihydroxy-3,6-dimethylbenzoate, methyl 3-formyl-2,4-dihydroxy-6-methylbenzoate, ethyl 3-formyl-2,4-dihydroxy-6-methylbenzoate, and lobaric acid had high gastrointestinal absorption, had high gastrointestinal absorption, in which these compounds exist in low concentrations in the blood.

Methyl 2,4-dihydroxy-3,6-dimethylbenzoate was able to cross the blood-brain barrier (BBB) due to the presence of a methyl group in the para position. Compounds permeating BBB by diffusion through lipids have molecular weights of $<400 \mathrm{Da}$ and hydrogen bonds of $<8$ (Pardridge, 2012). 
P-glycoprotein substrates are one of the drug-carrying proteins that affect drug distribution. This process affects plasma $\mathrm{P}$-glycoprotein substrates as a transmembrane pump, which pumps the substrate from within to outside the cell (Finch and Pillans, 2014).

From the prediction above, lobarin and lobaric acid were metabolized in CYP2C19, CYP3A4, and CYP2C9. CYP1 and CYP4 families-cytochrome P450 enzymes-are involved in drug metabolism, and the specific CYP2C9, CYP2C19, CYP2D6, and CYP3A4 isoenzymes are classified into the phase 1 metabolism (Waller and Sampson, 2018). Lobarin, methyl 2,4-dihydroxy-3,6dimethylbenzoate, and lobaric acid contain alkyl groups that play a role in oxidation reactions. Atranorin, methyl 3-formyl-2,4-dihydroxy-6-methylbenzoate, and ethyl 3-formyl-2,4-dihydroxy-6methylbenzoate have aldehyde groups that prompt reduction reactions.

CYP2C19 contributes to the metabolism of drugs, such as antiepileptic (S-mephenytoin and diazepam), proton pump inhibitors (omeprazole), amitriptyline, citalopram, and propranolol (Grody, 2018). CYP2C9 cytochrome is a vital drug metabolism enzyme in the human body and comprises around $18 \%$ of human microsomes (Lee et al., 2003). The metabolisms of nonsteroidal antiinflammatory drugs, losartan, tolbutamide, warfarin, and carbamazepine take place in CYP2C9 cytochrome (Yuan et al., 2002). CYP3A4 is involved in about 50\% oxidative metabolisms of HIV protease inhibitors, calcium channel blockers (nifedipine), hydroxymethylglutaryl inhibitors, coenzyme A reductase, antineoplastic drugs (cyclophosphamide, ifosfamide, docetaxel, paclitaxel, doxorubicin, etoposide, teniposide or vinca alkaloids), and the metabolisms of, among others, testosterone and aflatoxin (Georg Hempel, 2004). CYP3A4 is found most commonly in the liver, small intestine, and kidney (Thummel and Wilkinson, 1998).

Lobaric acid had the highest log Kp, meaning that it has the slowest skin penetration rate among the other compounds. On the contrary, methyl 3-formyl-2,4-dihydroxy-6-methylbenzoate had the lowest log $\mathrm{Kp}$ value or, in other terms, the fastest skin penetration rate. Log $\mathrm{Kp}$ is the logarithmic coefficient of skin permeability (Kp) expressed in $\mathrm{cm} / \mathrm{s}$. In this study, it was obtained using the quantitative structure-activity relationship (QSAR) method by modeling the influencing factors of skin permeability, including molecular mass, melting point, and the log value of the octanol-water partition coefficient (Chang et al., 2012).

Table 3. The predicted drug-likeness and medicinal chemistry of compounds isolated from Stereocaulon halei

\begin{tabular}{|c|c|c|c|c|c|c|}
\hline \multirow[b]{2}{*}{ Compound } & \multicolumn{3}{|c|}{ Drug-likeness } & \multicolumn{3}{|c|}{ Medicinal chemistry } \\
\hline & Egan & Muegge & Bioavailability & PAINS & Brenk Filters & $\begin{array}{l}\text { Difficulty } \\
\text { in being } \\
\text { synthesized }\end{array}$ \\
\hline 1 & $\begin{array}{c}\text { No, } \\
\text { TPSA }>131.6\end{array}$ & No, $X \log p 3>5$ & 0.56 & 0 Alert & 0 Alert & 4.42 \\
\hline 2 & Yes & Yes & 0.55 & 0 Alert & $\begin{array}{l}\text { Aldehydes } \\
\text { and phenol }\end{array}$ & 2.93 \\
\hline 3 & Yes & $\begin{array}{c}\text { No. } \\
M w<200\end{array}$ & 0.55 & 0 Alert & 0 Alert & 1.81 \\
\hline 4 & Yes & Yes & 0.55 & 0 Alert & Aldehyde & 1.84 \\
\hline 5 & Yes & Yes & 0.55 & 0 Alert & Aldehyde & 2.05 \\
\hline 6 & Yes & No, Xlogp $3>5$ & 0.56 & 0 Alert & Phenol & 4.11 \\
\hline
\end{tabular}

Drug-likeness is the balance of molecular and structural properties that determine whether or not a drug molecule is similar to a currently or previously used drug. This study used the drug-likeness analysis proposed by Egan (Pharmacia) and Muegge and bioavailability prediction. The results are presented in Table 3. The Egan's drug-likeness estimation proved that Lobarin did not meet the 
requirements of drug-likeness because its TPSA was above 131.6. Meanwhile, the Muegge's druglikeness database showed that there were three compounds, including Lobarin, Methyl 2,4-dihydroxy3,6- dimethylbenzoate, and lobaric acid, that did not meet the requirements of drug-likesness because Lobarin and Lobaric Acid have $\log p$ values were greater than 5. Methyl 2,4- dihydroxy-3,6dimethylbenzoate has molecular weights were less than $200 \mathrm{~g} / \mathrm{mol}$. Bayern also uses Muegge's druglikeness method (Daina et al., 2017).

The bioavailability values of the compounds were 0.55 and 0.56 . Compounds No. 2,3,4, and 5 had the bioavailability value of 0.55 and not negative charge (at $\mathrm{pH} \mathrm{6)}$; hence, the requirements of good medicine were met. Compounds No. 1 and 6, i.e., lobarin and lobaric acid, had the bioavailability value of 0.56 , negative charge of -1 or -2 (at $\mathrm{pH}$ ), and PSA between $>75$ and $<150 \AA^{2}$ (Martin, 2005).

No compounds were categorized into Pan-Assay Interference Compounds (PAINS). PAINS are compounds that exhibit specific targets and often give false-positive results (hit identification) in High Throughput Screening (HTS) screening (Koptelov et al., 2018). The Brenk filters, containing a database of 105 fragments (Brenk et al., 2008), aims to find structural alerts of potential toxic effects of the compound observed. Structural alerts are chemical structures that indicate the toxic nature of a compound, in which part of the structure that has mutagenic and carcinogenic potentials is identified. The aldehydic group can lead to the formation of a Schiff base with a primary amine. This is considered potentially genotoxic, as demonstrated in vivo by the ability to react with nucleobases without metabolic activation, interbase cross-links, and adducts formation (Speit et al., 2007) According to an in vitro test at the HGPRT locus of V79 Chinese hamster cells, phenol is reported to have mutagenic properties in the liver (Paschin and Bahitova, 1982). Based on the Brenk's filters, atranorin contained structural alerts of aldehyde and phenol structural alerts; methyl 3-formyl-2,4-dihydroxy-6-methylbenzoate and ethyl 3-formyl-2,4-dihydroxy-6-methylbenzoate had structural alerts of aldehyde; and lobaric acid had structural alerts of phenol.

The degree to which a compound is difficult to synthesize ranges between 1 (very easy) to 10 (very difficult). Its determination takes into account the factors of complexity, such as macrocyclic, chiral center (Ertl and Schuffenhauer, 2009). Based on this degree, the most easily synthesized compound was compound No. 3, followed by 4,5,2,6, and then 1 .

\section{Docking}

The docking simulation produced 20 docking poses with different binding energies that were mostly negative because of the presence of strong interaction. The Gibbs free energies identified in this study are presented in Table 4.

Table 4. The Gibbs free energy $(\Delta G)$ obtained from the docking simulation of compounds isolated from Stereocaulon halei

\begin{tabular}{lc}
\hline \multicolumn{1}{c}{ Compounds } & Gibbs free energy \\
\hline Lobarin & -6.7 \\
Atranorin & -7.0 \\
Methyl 2,4-dihydroxy-3,6-dimethylbenzoate & -5.9 \\
Methyl 3-formyl-2,4-dihydroxy-6-methylbenzoate & -5.9 \\
Ethyl 3-formyl-2,4-dihydroxy-6-methylbenzoate & -5.6 \\
Lobaric acid & -5.6 \\
\hline
\end{tabular}

The compounds in the order of the lowest to the highest $\Delta \mathrm{G}$ values are Atranorin (-7.0 $\mathrm{Kcal} / \mathrm{mol})$, Lobarin $(-6.7 \mathrm{Kcal} / \mathrm{mol})$, Methyl 2,4-dihydroxy-3,6-dimethylbenzoate $(5.9 \mathrm{Kcal} / \mathrm{mol})$, Methyl 3-formyl-2,4-dihydroxy-6-methylbenzoate (-5.9 Kcal/mol), Ethyl 3-formyl-2,4-dihydroxy-6methylbenzoate $(-5.6 \mathrm{Kcal} / \mathrm{mol})$, and Lobaric acid $(-5.6 \mathrm{Kcal} / \mathrm{mol})$. Therefore, among these compounds, Atranorin has the best stability. 
The best compound that can inhibit receptors by spontaneously forming bonding energy was selected according to the lowest Gibbs free energy. Based on the results of the study, Atranorin had the lowest Gibbs free energy $(-7.0 \mathrm{kcal} / \mathrm{mol})$ among the other test ligands. Hydrogen bonding is an interaction that occurs between two molecules, each acting as a donor and an acceptor. Hydrogen bonds are formed as hydrogen binds atoms like fluorine $(\mathrm{F})$, nitrogen $(\mathrm{N})$, and oxygen $(\mathrm{O})$ (Głowacki et al., 2013).

Root Mean Square Deviation (RMSD) was calculated to quantify the experimental value that evaluates whether or not the docking program can produce a pose that is close to the native conformation. A real-native conformation is achieved if RMSD relative to the native pose is $\leq 2.0 \AA$ (Bell and Zhang, 2019). At this state, the docking poses produced are expected to have the lowest RMSD cut-off value $\leq 2.0 \AA$ (Angstrom).

As visualized and calculated using the Discovery Studio program, the hydrogen bonding between the test ligand and amino acid residues at the receptor was indicated by a green line. The identified ligand-receptor interactions are presented in Table 5.

Table 5. The ligand-receptor interactions and number of hydrogen bonding in compounds isolated from Stereocaulon halei

\begin{tabular}{lcc}
\hline \multicolumn{1}{c}{ Compounds } & $\begin{array}{c}\text { Hydrogen } \\
\text { Bonding }\end{array}$ & $\begin{array}{c}\text { Amino acids and } \\
\text { functional groups }\end{array}$ \\
\hline Lobarin & 5 & LYS575-O \\
& & LYS575-O \\
& & GLN556-O \\
& & SER487-O \\
Atranorin & 4 & TYR448-O \\
& & ARG328-O \\
& & ARG332-O \\
Methyl & 4 & ALA392-O \\
dimethylbenzoate & & GLU391-O \\
& & ARG328-O \\
2,4-dihydroxy-3,6- & & ARG332-H \\
Methyl & & ASP173-H \\
3-formyl-2,4-dihydroxy-6-methylbenzoate & 4 & GLY397-H \\
& & ARG332-O \\
Ethyl & & ARG332-O \\
methylbenzoate & & ALA392-H \\
Lobaric acid & 2 & ASP173-H \\
& & ARG332-O \\
& & ARG328-O \\
& & ALA590-O \\
& & SER594-O \\
\end{tabular}

Apart from the formation of hydrogen bonds between ligands with protein, visualization using the Discovery Studio 2016 also displayed any amino acid residues involved in hydrophobic interactions. The amino acid residues that interacted with the ligand are listed in Table 6. 
Table 6. Amino acid residues of the compounds isolated from Stereocaulon halei that are involved in hydrophobic interactions with ligands

Compounds

Lobarin
Atranorin
Methyl 2,4-dihydroxy-3,6-
dimethylbenzoate

Methyl

3-formyl-2,4-dihydroxy-6-methylbenzoate Ethyl 3-formyl-2,4-dihydroxy-6methylbenzoate

Lobaric acid
Amino Acid Residues

GLN556. LYS575. SER487. TYR448.

ARG328. ARG332. ALA329. GLU391. ILE401

ARG328. ARG332. ALA392 ASP173.

GLU391. GLY397. GLU394. ILE401. TRP563. TYR177. SER170.

VAL393.VAL402

ARG332. ALA392. ASP173.

ILE401.GLU394. GLY397. VAL402

TRP563. ILE401. ARG332. ARG328

ALA509. GLU553. ILE496. LEU495. PHE550. SER594. VAL586

\section{CONCLUSIONS}

Lobarin does not fulfill the requirements of the Egan and Muegge's drug-likeness. The compounds isolated from Stereocaulon halei are Atranorin, Lobarin, Methyl 2,4-dihydroxy-3,6dimethylbenzoate, Methyl 3-formyl-2,4-dihydroxy-6-methylbenzoate, Ethyl 3-formyl-2,4-dihydroxy6-methylbenzoate, and Lobaric acid, with the Gibbs free energy of -7.0, -6.7, -5.9, -5.9, -5.6, and -5.6 $\mathrm{kcal} / \mathrm{mol}$, respectively. Based on the results of screening and visualization between the ligand and the protein, the general interactions that occur are in the form of hydrogen bonds and hydrophobic interactions. Further research is required so as to find out other parameters and the active site of the enzyme that a good inhibitor must have and to determine the stability of the ligand-protein bonds, especially in Atranorin.

\section{REFERENCE}

Bell, E. W., \& Zhang, Y. (2019). DockRMSD: An open-source tool for atom mapping and RMSD calculation of symmetric molecules through graph isomorphism. Journal of Cheminformatics, 11(1). https://doi.org/10.1186/s13321-019-0362-7.

Brenk, R., Schipani, A., James, D., Krasowski, A., Gilbert, I. H., Frearson, J., \& Wyatt, P. G. (2008). Lessons learnt from assembling screening libraries for drug discovery for neglected diseases. ChemMedChem, 3(3), 435-444. https://doi.org/10.1002/cmdc.200700139.

Chang, Y. C., Chen, C. P., \& Chen, C. C. (2012). Predicting skin permeability of chemical substances using a quantitative structure-activity relationship. Procedia Engineering, 45, 875-879. https://doi.org/10.1016/j.proeng.2012.08.252.

Daina, A., Michielin, O., \& Zoete, V. (2017). SwissADME: A free web tool to evaluate pharmacokinetics, drug-likeness and medicinal chemistry friendliness of small molecules. Scientific Reports, 7. https://doi.org/10.1038/srep42717.

Dunford, D., Dale, B., Stylianou, N., Lowther, E., Ahmed, M., \& Arenas, I. de la T. (2020). Coronavirus: The world in lockdown in maps and charts.

El-Masri, H. (2013). Modeling for regulatory purposes (risk and safety assessment). Methods in Molecular Biology, 930, 297-303. https://doi.org/10.1007/978-1-62703-059-5_13.

Ertl, P., \& Schuffenhauer, A. (2009). Estimation of synthetic accessibility score of drug-like molecules based on molecular complexity and fragment contributions. Journal of Cheminformatics, 1(1). https://doi.org/10.1186/1758-2946-1-8.

Finch, A., \& Pillans, P. (2014). P-glycoprotein and its role in drug-drug interactions. Australian 
Prescriber, 37(4), 137-139. https://doi.org/10.18773/austprescr.2014.050.

Georg Hempel. (2004). Drug Monitoring and Clinical Chemistry. Elsevier B.V.

Głowacki, E. D., Irimia-Vladu, M., Bauer, S., \& Sariciftci, N. S. (2013). Hydrogen-bonds in molecular solids-from biological systems to organic electronics. Journal of Materials Chemistry B, 1(31), 3742-3753. https://doi.org/10.1039/c3tb20193g.

Grody, R. P. B. K. W. (Ed.). (2018). Emery and Rimoin's Principles and Practice of Medical Genetics and Genomics (7th Editio). Academic Press.

Hirtz, J. (1985). The gastrointestinal absorption of drugs in man: a review of current concepts and methods of investigation. British Journal of Clinical Pharmacology, 19(2 S), 77S-83S. https://doi.org/10.1111/j.1365-2125.1985.tb02746.x.

Hopkins, J. (2020). COVID-19 Dashboard by the Center for Systems Science and Engineering (CSSE)..

Ismed, F., Lohezic-Le Devehat, F., Delalande, O., Sinbandhit, S., Bakhtiar, A., \& Boustie, J. (2012). Lobarin from the Sumatran lichen, Stereocaulon halei. Fitoterapia, 83(8), 1693-1698. https://doi.org/10.1016/j.fitote.2012.09.025.

Koptelov, M., Zimmermann, A., Bonnet, P., Bureau, R., \& Crémilleux, B. (2018). PrePeP - A tool for the identification and characterization of pan assay interference compounds. Proceedings of the ACM SIGKDD International Conference on Knowledge Discovery and Data Mining, 462-471. https://doi.org/10.1145/3219819.3219849.

Lee, C. B., Pieper, J. A., Frye, R. F., Hinderliter, A. L., Blaisdell, J. A., \& Goldstein, J. A. (2003). Tolbutamide, flurbiprofen, and losartan as probes of CYP2C9 activity in humans. Journal of Clinical Pharmacology, 43(1), 84-91. https://doi.org/10.1177/0091270002239710.

Lipinski, C. A. (2004). Lead- and drug-like compounds: The rule-of-five revolution. Drug Discovery Today: Technologies, 1(4), 337-341. https://doi.org/10.1016/j.ddtec.2004.11.007.

Martin, Y. C. (2005). A bioavailability score. Journal of Medicinal Chemistry, 48(9), 3164-3170. https://doi.org/10.1021/jm0492002.

Odimegwu, D. C., Ejikeugwu, C., \& Esimone, C. C. (2015). Lichen secondary metabolites as possible antiviral agents. Lichen Secondary Metabolites: Bioactive Properties and Pharmaceutical Potential, 165-177. https://doi.org/10.1007/978-3-319-13374-4_7.

Pajouhesh, H., \& Lenz, G. R. (2005). Medicinal chemical properties of successful central nervous system drugs. NeuroRx, 2(4), 541-553. https://doi.org/10.1602/neurorx.2.4.541.

Pardridge, W. M. (2012). Drug transport across the blood-brain barrier. Journal of Cerebral Blood Flow and Metabolism, 32(11), 1959-1972. https://doi.org/10.1038/jcbfm.2012.126.

Paschin, Y. V., \& Bahitova, L. M. (1982). Mutagenicity of benzo[a]pyrene and the antioxidant phenol at the HGPRT locus of V79 Chinese hamster cells. Mutation Research Letters, 104(6), 389-393. https://doi.org/10.1016/0165-7992(82)90175-0.

Patrick, G. L. (2013). An Introduction to Medicinal Chemistry (Fifth Edit). Oxford.

Prasanna, S., \& Doerksen, R. (2008). Topological Polar Surface Area: A Useful Descriptor in 2DQSAR. Current Medicinal Chemistry, https://doi.org/10.2174/092986709787002817.

Ranković, B. (2015). Lichen Secondary Metabolites (1st ed.). Springer International Publishing.

Speit, G., Schütz, P., Högel, J., \& Schmid, O. (2007). Characterization of the genotoxic potential of formaldehyde in V79 cells. Mutagenesis, 22(6), 387-394. https://doi.org/10.1093/mutage/gem031.

Thummel, K. E., \& Wilkinson, G. R. (1998). In vitro and in vivo drug interactions involving human CYP3A. Annual Review of Pharmacology and Toxicology, 38, 389-430. https://doi.org/10.1146/annurev.pharmtox.38.1.389.

Waller, D. G., \& Sampson, A. P. (2018). Medical Pharmacology \& Therapeutics (Fifth Edit). Elsevier.

Wan, Y., Shang, J., Graham, R., Baric, R. S., \& Li, F. (2020). Receptor Recognition by the Novel Coronavirus from Wuhan: an Analysis Based on Decade-Long Structural Studies of SARS 
Coronavirus. Journal of Virology, 94(7). https://doi.org/10.1128/jvi.00127-20.

Yuan, R., Madani, S., Wei, X. X., Reynolds, K., \& Huang, S. M. (2002). Evaluation of cytochrome p450 probe substrates commonly used by the pharmaceutical industry to study in vitro drug interactions. Drug Metabolism and Disposition, 30(12), 1311-1319. https://doi.org/10.1124/dmd.30.12.1311.

Zhao, Y., Zhao, Z., Wang, Y., Zhou, Y., Ma, Y., \& Zuo, W. (2020). Single-cell RNA expression profiling of ACE2, the putative receptor of Wuhan 2019-nCov. bioRxiv, 2020.01.26.919985. https://doi.org/10.1101/2020.01.26.919985. 
